\title{
Sam's progress with learning mathematics
}

\section{Lynne Haslam}

\begin{abstract}
Sam is 18 years old and has Down syndrome. He achieved a grade in the standard assessment of mathematics (GCSE) at 16 years of age. This paper describes the part played in his success in school by the Kumon method of teaching mathematics, identifies the benefits of the small steps and lots of practice built in to the method and illustrates the way Sam applied his Kumon learning in school.
\end{abstract}

Sam is now 18 and, since September 2006, has attended Foxes Academy in Minehead in south west England. Foxes Academy is a training hotel and catering college that teaches young people with learning disabilities ${ }^{[1]}$. Until Sam was 16 , he attended Altwood Church of England Comprehensive School in Maidenhead where he "passed" GCSE mathematics with Grade F. Incidentally, he also "passed" 7 other subjects getting grades of $\mathrm{E}$ or $\mathrm{F}$ but maths was probably his greatest achievement. So how did all this come about for a student with Down syndrome?

Well Sam started at his local mainstream school aged 5 and it soon became apparent that maths was not going to be his strongest subject. (Actually he was not a great reader either despite having followed early reading advice since he was 6 months old.) His cousins are half Japanese and virtually all Japanese pupils do Kumon maths after school so like them, aged 6, Sam began Kumon.

For those who do not know, "At the heart of the Kumon method of learning is the idea that each individual child can reach his or her potential, if given the right support and conditions. Kumon's programmes aim to increase self-confidence and empower students with the skills to learn for themselves."[2]

\section{Small steps and practice}

Basically that means intensive (daily) practice of written mathematical "sums". It sounds tedious and boring and to a certain extent it is. However, the achievements are worthwhile and the improvement in self esteem is huge. As the work is graded in such small steps, it is possible to achieve again and again. Each child starts at the simplest level (for Sam this was learning to count and then count on from any given number eventually up to 100) and pupils are supposed to complete a set number of sheets of work each day, each sheet of about $10-20$ questions practising the same skill. The work is graded in the tiniest possible steps and Sam's Kumon instructor (who was not a trained teacher) allowed us to repeat the steps as often as I felt necessary. Children attend a Kumon centre once a week and are supposed to work on that day's task unaided although I generally accompanied Sam. There is no doubt that the method is very tedious and that our patience was sorely tested at times. Work has to be completed every day and I mean every day. Sam has a sister 14 months younger and a brother 2 years younger so they all ended up doing Kumon. It must be admitted that I was the person who paced Sam's work - it is supposed to take 10 minutes but sometimes took up to half an hour depending on his frame of mind. As many parents will know, many youngsters can be extremely stubborn at times and Sam is no exception.

However, Sam's Kumon instructor was very flexible and Sam gradually learned, over the next 4 years, how to count, add up, subtract and multiply (even long multiplication) thousands, hundreds, tens and units. He never mastered division and still has not done so. We did not reach the fraction section although I know of two other children with Down syndrome who have continued with the programme and can do fractions as well.

\section{Abstract concepts}

I am a qualified primary teacher and in many ways this method of old fashioned pages of "sums" flies in the face of all good educational practice in that there is no physical manipulation of objects involved. No "concrete to abstract" ideas but, in a way, that is why it succeeds. Sam

\section{Kumon}

A teaching programme that emphasises a step-by-step approach, building on success and learning through practice.

\section{GSCE}

General Certificate of Secondary Education, graded $A^{*}$ to $G$, the subject based examinations pupils normally take at the end of Key Stage 4, age 16. 


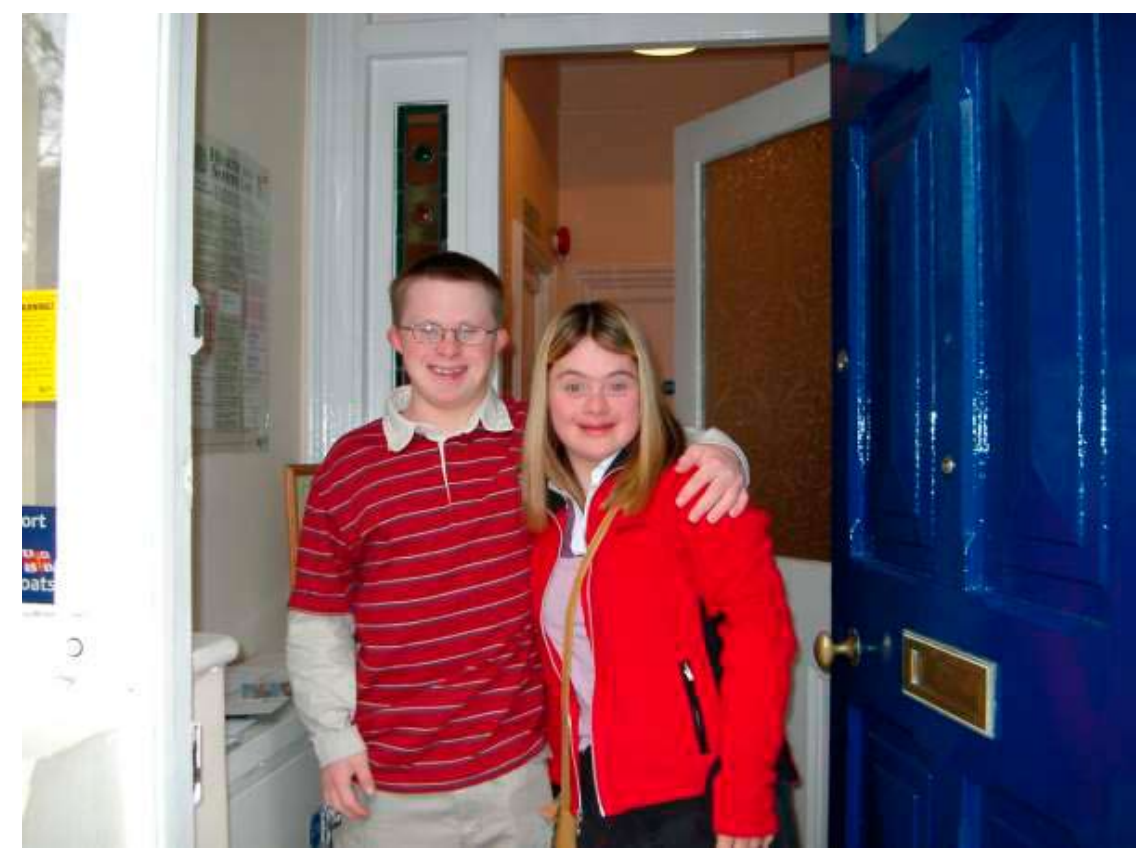

Sam in Minehead, when visited by his girlfriend of the last 2 years, Judith

was neither distracted nor confused by trying to extrapolate abstract from concrete. He learned to count and manipulate numbers and retained that skill and could apply it to real situations when they arose. e.g. "You have 12p, how much more do you need to buy something costing 19 p?" He could count on from 12 p yet Kumon does not include work on money - why would it? It is the same skill as manipulating any numbers. At the end of each session, children do have the opportunity to place 100 magnetic numbers on a magnetic number board. This helps them understand numbers, odd and even and other concepts. This is a timed activity and although there is no obvious aim in the activity, it can be what you make it. We bought a number board for practice at home.

We stopped going to Kumon soon after starting secondary school because of the demands of homework, but we still have a number of extra sheets and occasionally, Sam still completes some of these. At secondary school, he astonished the history staff in being able to calculate the success of medieval monarchs using a tally chart - the same skill as he learned at Kumon but Kumon did not do tally charts.

The Kumon methodology did not require any different input from the school. Sam's primary teachers saw a great improvement in his achievement and reduced the amount of physical materials they used with Sam. Teachers recommended Kumon to other parents - many, many children of all abilities go to the classes. I do not think that the method suits all children and would not replace maths teaching in schools with Kumon, but many children, who struggle with maths, would benefit from its simplicity. In fact, many bright pupils surge ahead at school after following a Kumon programme and nearly all Japanese children do Kumon to stay ahead in class.

At least three other parents of children with Down syndrome have followed the Kumon programme but I am not aware of any studies which prove its efficacy for children with Down syndrome. It would make an interesting study but there are many other factors which govern success especially where the children are completing extra work outside the school environment. For Sam, however, the "proof of the pudding is in the eating" - he took and "passed" GCSE maths and I doubt he would have done so without Kumon maths.

1. Foxes Academy.[Online] 2007.[Cited: 12 Feb 2007] Available from: http://www.foxesacademy.ac.uk/.

2. Kumon Educational UK. Kumon Method. Kumon UK.[Online] 2005.[Cited: 12 Feb 2007] Available from: http://www.kumon.co.uk/aboutkumon/kumonmethod.asp.

Received: 5 February 2007; Accepted 14 February 2007 Published online: 30 July 2007.

\section{FURTHER INFORMATION}

Kumon Australia and New Zealand http://www.kumon.com.au/ Kumon España http://www.kumon.es/

Kumon Deutschland http://www.kumon.de/

Kumon North America http://www.kumon.com/

Kumon UK and Ireland http://www.kumon.co.uk/ 